\title{
A Rare Coexistence: Omphalomesenteric Remnant with Appendix and Caecum Duplication
}

Münevveroğlu $C^{*}$

Department of Pediatric Surgery, Istanbul Medipol University, İstanbul, Turkey

*Corresponding author: Münevveroğlu Ç, Department of Pediatric Surgery, Istanbul Medipol University, İstanbul, Turkey, E-mail: drcaglarm@gmail.com

Citation: Münevveroğlu Ç (2016) A Rare Coexistence: Omphalomesenteric Remnant with Appendix and Caecum Duplication. J Case Rep Stud 4(2): 206. doi: 10.15744/2348-9820.4.206

Received Date: March 04, 2016 Accepted Date: April 16, 2016 Published Date: April 19, 2016

\begin{abstract}
The nutrition source of developing embryo at early stages is the omphalomesenteric duct which obliterates latter. Failure of this obliteration process brings on omphalomesenteric remnants. Appendix anomalies, which include appendix duplications, are very rare. Usually severe intestinal, genitourinary and vertebral anomalies coexist with appendix duplications. The aim of this study is, to present a case of an infant who underwent surgery for operative repair of an omphalomesenteric remnant (omphalomesenteric fistula), and appendix and caecum duplication was diagnosed during surgery, to review the classification of appendix duplications and to call attention to coincidence of omphalomesenteric remnants and other congenital anomalies.

Keywords: Appendix; Caecum; Duplication; Omphalomesenteric Remnant; Omphalomesenteric Fistula
\end{abstract}

\section{Introduction}

The omphalomesenteric duct, which provides nutrition to the embryo at the early stages of development, separates from the intestine between the $5^{\text {th }}$ and $7^{\text {th }}$ weeks of gestation and is obliterated. Partial or complete failure of this obliteration process results in omphalomesenteric remnants and occurs in approximately $2 \%$ of new-borns [1]. Omphalomesenteric remnants include Meckel's diverticulum, omphalomesenteric fistula, omphalomesenteric sinus, omphalomesenteric cysts and congenital bands.

Appendix anomalies including appendix duplications are very rare and found between $0.004 \%$ and $0.009 \%$ incidentally during appendectomies [2-4]. Appendix duplications are classified with the modified Cave-Wallbridge Classification and serious intestinal, genitourinary and vertebral anomalies can accompany these duplications [5-7].

In 2014 Panda, et al. reported a case with coexistence of Meckel's diverticulum and appendix duplication but coexistence of omphalomesenteric fistula and appendix and caecum duplication (Type C appendix duplication) have not previously been reported in the literature [8].

\section{Case Report}

A 22 day-old male infant was referred to our clinic with faecal discharge from their child's umbilicus. He was born after 38 weeks of gestation vaginally. He weighted 2950 grams and his total height was $59 \mathrm{~cm}$ at birth. The pregnancy period of his mother was uneventful and the patient had no family history of congenital malformations. On his physical examination icterus and prolapse of a mucosal lumen with faecal discharge from the umbilicus was noticed. Length, width and depth of the prolapsed mucosa were 1x1x0.4 cm respectively. Other physical examination findings were normal (Figure 1).

The infant was diagnosed with an omphalomesenteric fistula and an operation was decided. Preoperative laboratory results of the patient were normal except hyperbilirubinemia (total bilirubin: $11.19 \mathrm{mg} / \mathrm{dL}$ ).

During exploratory laparotomy, a fistula between ileum and umbilicus was found at $80 \mathrm{~cm}$ proximal from terminal ileum (omphalomesenteric fistula). On further exploration appendix and caecum duplications were discovered (Figure 2). Sizes of the appendixes were $2 \times 0.3 \mathrm{~cm}$ and $1.5 \times 0.2 \mathrm{~cm}$ and length of the duplicated caecum was $2.5 \mathrm{~cm}$. According to modified Cave-Wallbridge classification this presentation corresponded precise to type $\mathrm{C}$ appendix duplication. No additional congential anomalies were discovered within the abdominal cavity. The connection of the omphalomesenteric fistula with umbilicus was dissected and wedge resection and anastomosis were performed to the ileal connection of the fistula. The excised omphalomesenteric fistula was sent for histopathological examination. No surgical intervention was performed to appendix and caecum duplication as no complications were discerned about them. An aesthetic appearance was given to the umbilical pit and the operation ended without complication. 




Figure 1: Prolapse of a mucosal lumen with faecal discharge from umbilicus noticed

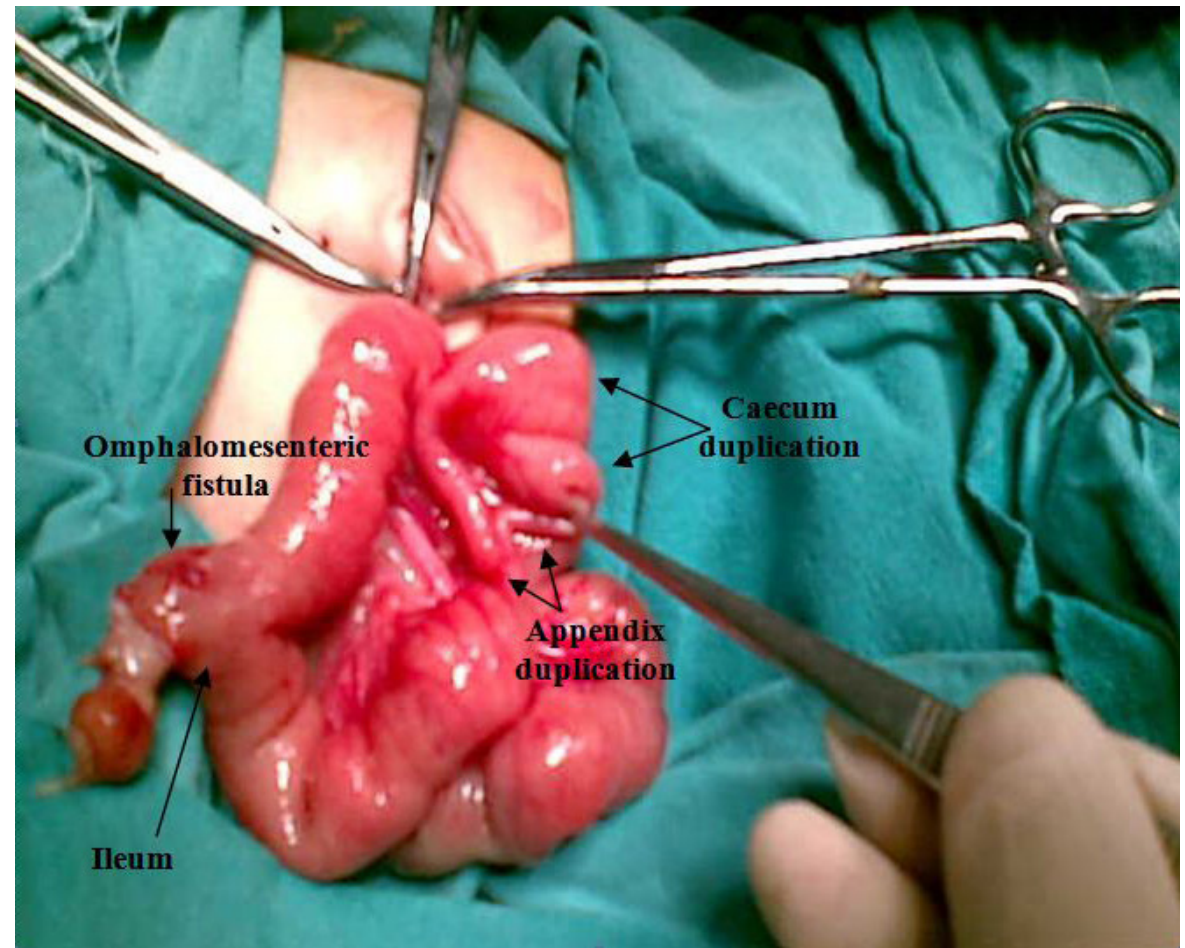

Figure 2: Omphalomesenteric fistula with appendix and caecum duplication noticed. (Colon is not clearly seen in this picture)

The patient's postoperative period was uneventful and the patient was discharged on the $7^{\text {th }}$ day after surgery. No genitourinary or vertebral anomaly was detected upon postoperative observation of our patient. The histopathological examination of the excised tissue reported as a chronic inflammatory omphalomesenteric duct.

\section{Discussion}

In the developing embryo, the omphalomesenteric duct connects the yolk sac to the gut and provides nutrition until the placenta is established. After the placenta occurs this duct attenuates, separates from the intestine and is obliterated totally between the $5^{\text {th }}$ and $7^{\text {th }}$ weeks of gestation [1]. Failure of this process results in omphalomesenteric remnants. The most common omphalomesenteric remnant is Meckel's diverticulum [1]. Nonetheless, omphalomesenteric fistula, sinus, cysts and congenital bands are the other omphalomesenteric remnants [9]. 
Clinical presentation of omphalomesenteric fistula is mostly a faecal drainage from the umbilicus as in our case [10]. Diagnosis and treatment of omphalomesenteric remnants are very important because of the possibility of severe, life-threatening complications like volvulus and intestinal herniation.

It has previously been reported that omphalomesenteric remnants may be associated with umbilical hernia, intestinal atresia, cardiac malformations, cleft lip and palate and exomphalos, but these coexistences are very rare and limited with only a few cases in the literature $[1,11]$. Although these accompaniments are very rare, a detailed physical examination of patients with omphalomesenteric remnants is very important and if a patient has symptoms or findings independent from omphalomesenteric remnants additional pre-operative workup must be done with these anomalies in mind. Also, surgeons must be mindful of coexisting intraabdominal anomalies during surgery of patients with omphalomesenteric fistula.

Appendix duplication is an extremely rare congenital anomaly and less than 100 cases have been reported in the literature till now [3,8]. Appendix duplications were first classified by Cave in 1936 based on their anatomical locations and in 1963 Wallbridge modified this classification [12,13]. This classification system also 'enriched' by Biermann in 1993 [8]. The most frequently utilized classification system of appendix duplications is the modified Cave-Wallbridge classification. More recently, cases that do not fit into this classification have been described as "horseshoe appendix" and "triple appendix" [14-16].

Most of the appendix duplications which have been diagnosed in childhood were accompanied by intestinal, genitourinary and vertebral anomalies [5-7]. These anomalies usually accompany type B1 and C appendix duplications [15,17-19]. There isn't enough data to explain the cause of this coincidence yet. This paper reports an omphalomesenteric fistula accompanying type $\mathrm{C}$ appendix duplication.

For type A and type B duplications some surgeons suggest appendectomy for both appendixes to avoid diagnostic confusion but some don't because most of appendix duplications remain silent for a life time. It is difficult to find caecum duplication alone in the literature so there isn't a consensus regarding the need for surgical management about this issue, but the recommended treatment of intestinal duplications is surgical excision to avoid complications like obstruction, bleeding, torsion and malignity. In our case, the patient was operated on for omphalomesenteric fistula that may cause life-threatening complications and type $\mathrm{C}$ appendix duplication was found incidentally during this operation. To avoid any enhanced morbidity to a new-born, resection of duplicated segment that did not inspire a surgical complication was pushed into the background with the plan of further surgical management.

We couldn't find a paper in the literature about omphalomesenteric fistula and Type $\mathrm{C}$ appendix duplication coexistence and consequently suggest that this can be identified as a new association. The embryological nature of an omphalomesenteric remnant and that of a duplicated appendix suggests a common underlying mechanism involving developmental malformation [8].

\section{Conclusion}

As a result, surgeons must be mindful of accompanying anomalies when attending to patients with omphalomesenteric fistula. Also, being aware of the patient having appendix duplication will be instructive for a future intestinal obstruction or acute abdomen.

\section{References}

1. Zafer Y, Yiğit S, Türken A, Tekinalp G (2000) Patent Omphalomesenteric duct. Turk J Med Sci 30: 83-5.

2. Collins DC (1955) A study of 50,000 specimens of the human vermiform appendix. Surg Gynecol Obstet 101: 437-45.

3. Kjossev KT, Losanoff JE (1996) Duplicated vermiform appendix. Br J Surg 83: 1259.

4. Griffiths EA, Jagadeesan J, Fasih T, Mercer-Jones M (2006) Bifid Vermiform Appendix: A case report. Curr Surg 63: 176-8.

5. Gilchrist BF1, Scriven R, Nguyen M, Nguyen V, Klotz D, et al. (1999) Duplication of the vermiform appendix in gastroschisis. J Am Coll Surg 189: 426.

6. Scarff JE Jr, Harrold MW, Wylie JH (1982) Duplication of the vermiform appendix: new variant of a rare anomaly. South Med J 75: 860-2.

7. Eroglu E, Erdogan E, Gundogdu G, Dervisoglu S, Yeker D, et al. (2002) Duplication of appendix vermiformis: a case in a child. Tech Coloproctol 6: 55-7.

8. Panda SK, Prasad C, Tirkey R, Rajesh V, Mishra J, et al. (2014) Unusual association of Meckel's diverticulum with double appendix - A rare finding. Int J Surg Case Rep 5: 879-81.

9. Abhyankar A, Lander AD (2004) Umbilical disorders. Surgery, Oxford University Press 22: 214-17.

10. O’Neill JA, Rowe MI, Grosfeld JL, Fonkalsrud EW, Coran AG (1998) Pediatric Surgery (5 ${ }^{\text {th }}$ ed). St. Louis: Mosby-Year Book.

11. Blair SP, Beasley SW (1997) Intussusception vitello-intestinal tract through and exomphalos in Trisomy 13. Pediatr Surg Int 4: 422-3.

12. Cave A (1936) Appendix vermiformis duplex. J Anat 70: 283-92.

13. Wallbridge PH (1962) Double appendix. Br J Surg 50: 346-7.

14. DasGupta R, Reber PU, Patel AG (1999) Horseshoe appendicitis. Eur J Surg 165: 1095-6.

15. Mesko TW, Lugo R, Breitholtz T (1989) Horseshoe anomaly of the appendix: a previously undescribed entity. Surgery 106: 563-6.

16. Tinckler LF (1968) Triple appendix vermiformis-a unique case. Br J Surg 55: 79-81.

17. Arda IS, Şenocak ME, Hiçsönmez A (1982) Duplication of vermiform appendix: case report and review of the literature. Pediatr Surg Int 7: 221-2.

18. Khannan AK (1983) Appendix vermiformix duplex. Postgrad Med J 59: 69-70. 
19. Rizalar R, Saraç A, Görk AS, Somuncu S, Bernay F, et al. (1996) Duplication of appendix with segmental dilatation of the colon, myeloschisis and anal atresia. Eur J Pediatr Surg 6: 112-3.

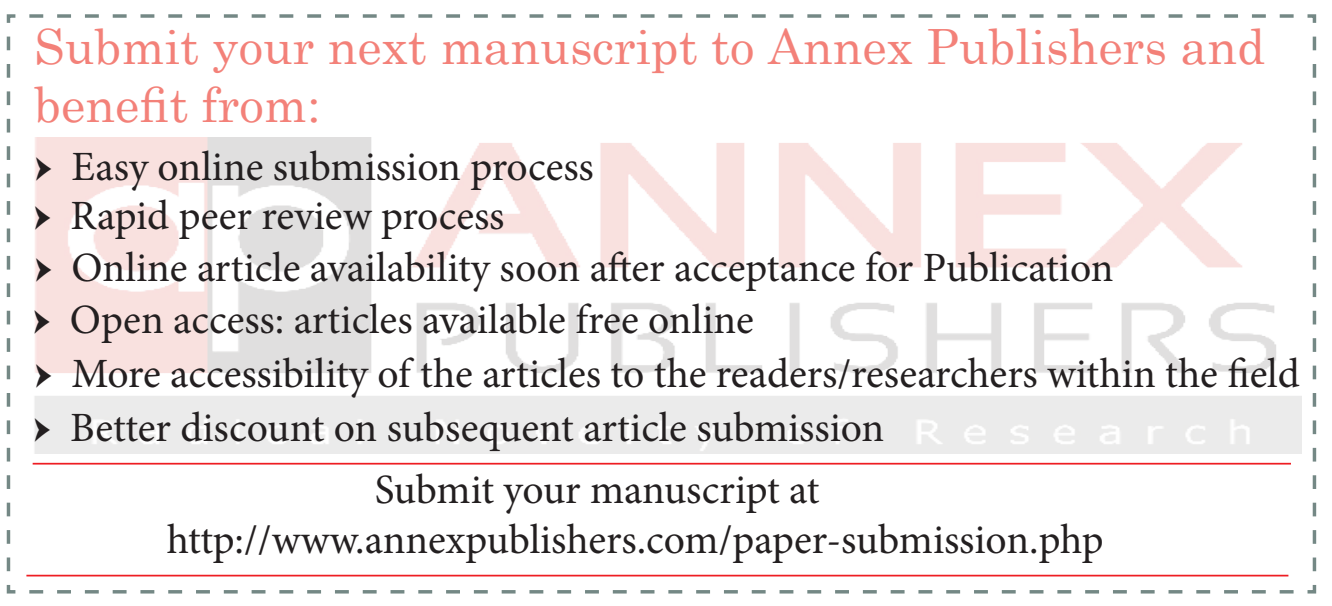

